\title{
Longevidade e espiritualidade: 0 envelhecer como uma dádiva de Deus
}

\author{
Maykon dos Santos Marinho*, Renato Novaes Chaves", Jamília Brito Gomes"**, Luciana Araújo dos Reis
}

\section{Resumo}

O envelhecer é percebido por alguns idosos como uma graça divina, um encontro espiritual e uma reverência a Deus. Assim, este estudo tem por objetivo analisar as percepções sobre o envelhecer dos idosos longevos. Trata-se de uma pesquisa qualitativa exploratório-descritiva, com a utilização da técnica da história oral temática e do software NVivo para análise dos dados. As entrevistas foram realizadas no período compreendido entre janeiro e maio de 2015. Participaram da pesquisa dez idosos longevos cadastrados em uma Unidade de Saúde da Família (USF) do município de Vitória da Conquista, Bahia, que atenderam aos seguintes critérios de inclusão: ter idade igual ou superior a 80 anos, ser independente funcionalmente e ser usuário da USF escolhida. Para os idosos longevos, o envelhecer está associado à espiritualidade e à crença de que a velhice é uma dádiva de Deus. Este estudo reafirma a importância de novos estudos com idosos longevos e a inclusão do tema da espiritualidade nos estudos sobre envelhecimento.

Palavras-chave: Envelhecimento. Espiritualidade. Velhice.

\section{Introdução}

Nos últimos dez anos, o Brasil apresentou um considerável crescimento do número de idosos, passando de um contingente de $9,8 \%$ da população, em 2005 , para $14,3 \%$, em 2015, o que deverá

* Mestre em Memória: Linguagem e Sociedade e doutorando no Programa de Pós-Graduação em Memória: Linguagem e Sociedade, da Universidade Estadual do Sudoeste da Bahia (Uesb), com bolsa Capes. Membro do Núcleo Interdisciplinar de Estudos e Pesquisa sobre Envelhecimento Humano (Uesb). Enfermeiro (Ufba). Endereço para correspondência: Universidade Estadual do Sudoeste da Bahia. Estrada do Bem Querer, Km 4, Lot. Itamarati, Vitória da Conquista, BA, 45083-900. E-mail: mayckon_ufba@hotmail.com

** Mestre em Memória: Linguagem e Sociedade e doutorando no Programa de Pós-Graduação em Memória: Linguagem e Sociedade, da Universidade Estadual do Sudoeste da Bahia (Uesb). Membro do Núcleo Interdisciplinar de Estudos e Pesquisa sobre Envelhecimento Humano (Uesb). Enfermeiro. E-mail: rncnovaes@ hotmail.com

*** Mestre em Memória: Linguagem e Sociedade, Universidade Estadual do Sudoeste da Bahia (Uesb). Psicóloga. E-mail: jamiliabg@hotmail.com

**** Especialista em Saúde Pública (Facinter). Especialista em Ativação de Processos de Mudança na Formação Saúde (Fiocruz). Mestre e doutora em Ciências da Saúde (UFRN), com pós-doutoramento em Saúde Coletiva (Ufba-ISC). Docente adjunta B do Curso de Fisioterapia (Uesb). Orientadora do Programa de Pós-Graduação em Memória: Linguagem e Sociedade (Uesb). Coordenadora do Núcleo de Estudos e Pesquisa sobre Envelhecimento e Obesidade. Pesquisadora líder do núcleo de extensão, pesquisa e estudos sobre Doenças Crônicas. Fisioterapeuta (Uesb). E-mail: lucianauesb@ yahoo.com.br

$\rightarrow$ http://dx.doi.org/10.5335/rbceh.v14i2.6702

Recebido em: 27.01.2017. Aceito em: 29.09.2017. 
ter continuidade nas próximas décadas, segundo as projeções do Instituto Brasileiro de Geografia e Estatística (BRASIL, 2016). Os idosos com 80 anos ou mais de idade compõem o grupo que mais cresceu significativamente (BRASIL, 2016).

$\mathrm{O}$ avanço da longevidade amplia a probabilidade de contato com eventos de perdas e a necessidade da utilização de recursos de enfrentamento para vivenciá-los, pois fatores como declínio da saúde física, mudanças psicológicas e sociais, perdas de amigos e pessoas da família podem conduzir a sentimentos negativos, tais como de abandono, de inutilidade, de falta de autonomia e de controle sobre si e seu meio (GUTZ; CAMARGO, 2013).

Por isso, para lidar com essas adversidades na velhice, a espiritualidade é contemplada como um dos enfrentamentos para situações adversas, constituindo-se de aspectos emocionais e motivacionais na busca de um significado para a vida (GUTZ; CAMARGO, 2013). Ao abordar o tema da espiritualidade na velhice, é importante conceituá-la, bem como fazer a distinção entre espiritualidade e religião.

De acordo com Gutz e Camargo (2013), as religiões dispõem de um código de ética que rege o comportamento e dita os valores morais, já a espiritualidade remete a uma questão universal relacionada ao significado e ao propósito da vida. Ela é uma reflexão sobre o significado da existência. Para Gall et al. (2011), a conexão com Deus ou um poder maior é considerada como um componente-chave da espiritualidade, estando associada ao eu e ao próprio modo de estar na vida.

De acordo com Biolchi et al. (2014), a fé e a espiritualidade são essenciais ao indivíduo, pois preenchem o incompleto ao mesmo tempo em que são auxiliadoras dos discursos de sentido para a continuidade da vida. Alguns estudos confirmam que o processo de envelhecer é percebido pelos idosos como uma graça divina, um encontro espiritual e uma reverência a Deus (FRUMI; CELICH, 2006; BIOLCHI et al., 2014).

A espiritualidade na velhice tem como função ser um recurso de enfrentamento facilitador de bem-estar, saúde, qualidade de vida, boa convivência familiar e social, para lidar com as adversidades decorrentes das limitações físicas, com perdas de pessoas próximas e com a proximidade da própria morte (GUTZ, CAMARGO, 2013). Dessa maneira, a espiritualidade contribui para a resiliência e um envelhecimento bem-sucedido, pois certos comportamentos e crenças religiosas estão diretamente relacionados com a felicidade geral e a saúde física (TOVAR-MURRAY, 2011).

A velhice tem sido bastante estudada devido ao aumento significativo da longevidade e, consequentemente, do número de idosos. Com isso, as contribuições acadêmicas têm sido importantes para o estudo sobre o envelhecimento. No entanto, ainda há escassez de pesquisas sobre espiritualidade/religiosidade exclusivamente em populações idosas (LUCCHETTI et al., 2011). Desse modo, surgiu a questão que norteia a abordagem deste estudo: qual o significado de 
envelhecer para os idosos longevos? Foi nesse viés que se pesquisou e que, no transcorrer dos discursos dos idosos longevos, foram obtidas as respostas para as questões levantadas, contribuindo para o enfoque interdisciplinar, complexo e plural da velhice. Sendo assim, o presente estudo teve como objetivo analisar as percepções de idosos longevos sobre 0 envelhecer.

\section{Metodologia}

Esta é uma pesquisa qualitativa exploratório-descritiva, com a utilização da técnica da história oral temática, que consiste na narrativa do conjunto das experiências de vida de uma pessoa. É um recurso moderno usado para a elaboração de registros, documentos, arquivamentos e estudos referentes à experiência social de pessoas e grupos (MEIHY, 2005).

Neste estudo, o campo de investigação foi uma Unidade de Saúde da Família (USF) do município de Vitória da Conquista, Bahia. Essa USF tem 3.392 famílias cadastradas, oferecendo atendimento para 13.146 usuários, dos quais 1.320 são idosos. Os participantes da pesquisa foram dez idosos longevos que atendiam aos seguintes critérios de inclusão: ter idade igual ou superior a 80 anos, ser independente funcionalmente e ser usuário da USF escolhida.

Foram utilizados dois instrumentos para a coleta de dados: um formulário semiestruturado, com questões de caracterização sociodemográfica dos idosos longevos, e uma entrevista semiestru- turada, com questões voltadas para os significados atribuídos ao processo de envelhecimento.

Após a transcrição integral das entrevistas, as informações foram analisadas utilizando a técnica de análise de conteúdo de Bardin (2011). Porém, devido à grande quantidade de informações, utilizou-se o software de tratamento de dados qualitativos QSR NVivo ${ }^{\boxplus}$, versão 10.0, doravante mencionado como NVivo.

O processo de análise de conteúdo foi operacionalizado em três etapas: pré-análise, exploração do material e tratamento dos resultados obtidos, inferência e interpretação (BARDIN, 2011). Na etapa de pré-análise, as transcrições foram transferidas para o NVivo com o recurso de importação de fontes de informação, compondo assim o corpus da pesquisa. Após a criação do banco de dados no NVivo, foi iniciada a etapa seguinte: a de exploração do material. Nessa etapa, foram realizados a leitura exaustiva das transcrições e o processo de codificação, com a decomposição dos conteúdos em unidades de registro, baseando-se nas expressões com sentidos equivalentes que surgiram ao longo do corpus da pesquisa, as quais foram agrupadas nas categorias analíticas emergentes dos dados empíricos.

Nessa etapa, foi utilizada a técnica "nuvens de palavras" do NVivo para análise do material empírico. Essa técnica pode ser compreendida como uma forma de visualização de dados linguísticos que mostra a frequência com que as palavras aparecem em um dado contexto. A técnica de construção dessa nuvem consiste 
em usar tamanhos e fontes de letras diferentes de acordo com as ocorrências das palavras na categoria analisada, o que gera uma imagem que apresenta um conjunto de palavras coletadas do corpo do texto e agregadas de acordo com sua frequência, sendo que as palavras mais frequentes aparecem no centro da imagem de modo decrescente, e as demais, em seu entorno (QRS INTERNACIONAL, 2014). Dessa maneira, a aplicabilidade dessa técnica contribui para a visualização do que é mais relevante nas falas dos participantes do presente estudo.

De posse da nuvem de palavras e dos dados codificados, foi iniciada a terceira e última etapa, a do tratamento dos resultados. Buscou-se a articulação entre o material empírico e o referencial teórico, possibilitando a ocorrência de outras contribuições teóricas sugeridas pela leitura do material empírico.

$\mathrm{O}$ desenvolvimento desta pesquisa respeitou a Resolução no 466, de 2012, do Conselho Nacional de Saúde. Assim, o projeto da pesquisa foi encaminhado ao Núcleo de Educação Permanente da Secretaria Municipal de Saúde do município de Vitória da Conquista, Bahia, e ao Comitê de Ética em Pesquisa da Faculdade Independente do Nordeste, obtendo o parecer de aprovação (Protocolo $\mathrm{n}$ - 759479). Os participantes deste estudo assinaram o termo de consentimento livre e esclarecido. Com vistas a garantir o anonimato dos participantes e facilitar a compreensão do leitor, foram atribuídos, aleatoriamente, nomes de flores aos idosos longevos, a saber: Cravo, Margarida,
Camélia, Angélica, Rosa, Lírio, Hortência, Violeta, Girassol e Jasmim.

\section{Resultados}

Ao analisar os resultados obtidos no presente estudo, pode-se perceber uma maior participação de mulheres, posto que, dos dez participantes da pesquisa, oito pertencem ao sexo feminino, o que mostra uma maior tendência das mulheres em alcançar a longevidade. Essa vantagem em relação ao sexo é coerente com o registro na literatura e decorre de inúmeros fatores, entre eles, a tendência do sexo feminino em se cuidar mais e melhor, buscar assistência médica ou apoio social (SANTOS et al., 2014).

Em relação ao estado civil dos idosos longevos, os dois homens são casados; e, das oito mulheres entrevistadas, três são casadas, uma vive em união estável e quatro são viúvas. Um dado interessante é que o sexo feminino, enquanto mais longevo, tende a viver a viuvez mais frequentemente que o masculino (BRASIL, 2010).

Em relação ao número de filhos, os idosos longevos entrevistados tiveram uma média de cinco filhos. Esses dados apontam para uma transição entre famílias extensas, com grande número de descendentes, para famílias menores, com um ou dois filhos por mulher na atualidade (BRASIL, 2010). Ao avaliar com quem o idoso longevo reside, parte significativa da amostra declarou morar com familiares. Entre eles, cinco vivem com seus cônjuges, três moram com parentes (filhos ou netos) e dois dizem 
morar sozinhos, e essa opção se deu pela fatalidade da viuvez ou pelo fato de os filhos morarem em outras cidades. Durante as narrativas, as idosas longevas afirmam preferir viver sozinhas, o fato de ter a sua própria moradia lhes dá autonomia e liberdade.

Essa preferência também foi constatada em pesquisas sobre idosos que moram sozinhos (SANTOS et al., 2010). A moradia representa a expressão da identidade e imprime as marcas pessoais, para a construção de um meio de proteção e de bem-estar, um espaço sob o próprio domínio e controle (SANTOS et al., 2010).

Com relação às profissões que exerceram, entre os entrevistados, um era comerciante, uma era professora, uma era costureira, uma era doméstica, um era policial e cinco eram donas de casa. Esse era o comportamento padrão nas décadas de 1930, 1940 e 1950 para as mulheres (BARROS, 2013). É importante registrar que todos os participantes deste estudo encontram-se cobertos pela seguridade social.

Quanto ao grau de escolaridade, dos dez entrevistados, quatro eram analfabetos, quatro tinham escolaridade equivalente ao ensino fundamental I, um tinha cursado o equivalente ao ensino fundamental II e outro o equivalente ao ensino médio. $\mathrm{O}$ baixo índice de educação formal dos idosos longevos entrevistados deve-se ao fato de que a maioria nasceu e viveu a infância em áreas rurais e em uma época na qual havia muita dificuldade de acesso ao ensino, carência de escolas públicas, baixo poder aquisitivo e desvalorização da educação formal. Essas situações, devido ao arraigado sistema patriarcal subjacente à sociedade brasileira até, pelo menos, a metade do século XX (FAORO, 1958), tornam-se mais graves para a conquista da educação formal entre o sexo feminino (VASCONCELOS; SOUZA FILHO, 2001).

Os idosos longevos pesquisados acreditam ter boa saúde, pois têm autonomia e são independentes funcionalmente. Entende-se como idoso independente funcionalmente aquele que é capaz de realizar atividades da vida diária sem dificuldades. Os graus de autonomia e independência são aspectos que influenciam na qualidade de vida das pessoas. Para Conceição (2010), autonomia e independência são conceitos interdependentes e referem-se à forma como cada pessoa consegue conduzir sua própria vida. Considera-se autonomia como a capacidade de tomar decisões e de executá-las, enquanto independência relaciona-se com a conformação física, mental e social para realizar atividades cotidianas.

Nessa perspectiva, Minayo e Coimbra Júnior (2002) afirmam que, do ponto de vista econômico, os idosos (especialmente os mais ativos e independentes) representam um mercado promissor no mundo dos bens de consumo, da cultura, do lazer, da estética e dos serviços de saúde. Por conseguinte, garantir uma existência mais saudável ao idoso é admitir novas formas de pertencimento social, seja por meio das novas possibilidades de comunicação, de participação 
grupal ou, ainda, do cultivo de diferentes (ou novas) formas de lazer (MINAYO; COIMBRA JÚNIOR, 2002).

\section{Discussão}

O resultado gerado pela técnica nuvem de palavras (Figura 1) apontou que a palavra mais frequente nos depoimentos dos idosos longevos foi "Deus", associando a percepção do envelhecer à ideia central da existência de Deus.

Figura 1 -Nuvem de palavras gerada pelo NVivo com base nas narrativas dos idosos longevos

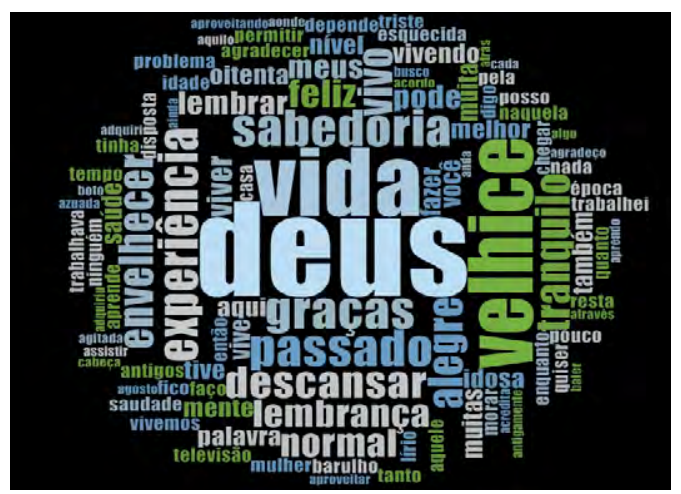

Fonte: dados da pesquisa "Narrativas sobre o envelhecer: memórias, vivências e identidades de idosos longevos”, realizada em Vitória da Conquista, em 2015.

Sendo assim, as narrativas dos idosos longevos indicam que o envelhecer está associado à espiritualidade, pois a velhice é sentida como um privilégio. É possível perceber, nas narrativas, de forma geral, o valor e a importância que são dados para a espiritualidade nessa fase da vida. Dos dez idosos longevos entrevistados, sete perceberam o envelhecer como uma graça divina, evidenciando assim os aspectos de reverência a Deus.
Segundo Mello e Araújo (2013), a espiritualidade na velhice é vivida, em primeiro lugar, no contato íntimo com Deus, pois, para os idosos, a fé em Deus é o alimento da alma, que pode favorecer a capacidade para os enfrentamentos da vida. Assim, a reverência a Deus e a gratidão por alcançar uma longevidade saudável conferem sentido à vida na velhice (BRANDÃO, 2011). Na percepção dos idosos participantes deste estudo, a velhice com saúde está relacionada à fé em Deus e à crença de ser ela (a velhice) uma dádiva de Deus, como podemos observar nas narrativas a seguir:

Eu encaro a velhice numa boa, pra mim o importante é que eu estou vivendo. Eu agradeço a Deus pela vida que ele está me dando, pela minha família, muito obrigado Senhor (Camélia, 83 anos).

Eu me sinto bem, né?! Me sinto bem, porque eu tenho muito que agradecer a Deus, porque eu já tô com meus oitenta anos e estou vivendo bem, com saúde (Margarida, 82 anos).

A velhice, eu acho que é uma coisa muito boa e agradecer a Deus por chegar aonde eu já cheguei, oitenta e um anos, não tenho o que falar da velhice não, eu acho que [...] pra mim tanto faz quando nova ou agora. Pra mim, é a mesma coisa (Rosa, 81 anos).

Eu vivo alegre, graças a Deus! Eu vivo com Deus e vivo alegre, eu e meu esposo, nós tem sessenta anos de casados, vivemos até hoje, nunca separamos, vivemos juntos até hoje e até o dia que Deus quiser e permitir, mesmo doente como ele tá, assim, na cama, mas eu não fico triste não. Ele tem problema de saúde, tem diabetes; tem um ano e meio que ele não anda, e é eu que cuido dele até quando Deus permitir (Violeta, 82 anos).

Eu me sinto feliz, porque se eu tô envelhecendo é porque Deus me permitiu vida até aqui (Girassol, 81 anos). 
Percebe-se, nas narrativas dos idosos longevos, que a velhice, embora seja marcada pelas singularidades e experiências de vida individuais e coletivas de cada idoso ao longo do tempo, quando alcançada com uma boa qualidade de vida, está associada com a espiritualidade e a crença em Deus. Ou seja, nota-se que essas similitudes refletem que o processo de envelhecer foi marcado pela interferência cultural e religiosa dos grupos sociais nos quais os sujeitos estavam inseridos, o que corrobora com os estudos realizados por Mello e Araújo (2013) e Chaves e Gil (2015), que afirmam que o processo de envelhecer saudável está associado à vontade divina e denotam valor e importância à vivência da espiritualidade nessa fase da vida.

Nesse sentido, um estudo sobre o significado da velhice com 48 idosos de zona rural no Ceará revelou que o envelhecimento saudável, para o grupo pesquisado, está associado a uma dádiva de Deus, demonstrando que as percepções dos idosos sobre o envelhecer são marcadas por uma nítida concepção religiosa. Contudo, os autores ressaltam que o envelhecimento é considerado um processo permeado por alterações durante o curso de vida dos indivíduos, e por isso o contexto particular contribui muito para o modo como se percebe o mundo e a si mesmo (FREITAS; QUEIROZ; SOUSA, 2010).

Dessa forma, corroborando o estudo de Freitas, Queiroz e Sousa (2010), quando os longevos desta pesquisa percebem o envelhecer como uma dádiva de Deus, estão falando a partir de suas representações religiosas marcadas por uma interação social estabelecida a partir das experiências nos grupos sociais nos quais eles se constituíram enquanto indivíduos. Em alguns momentos das narrativas dos idosos longevos, a figura de Deus não é referenciada efetivamente, mas aparece como expressões idiomáticas recorrentes, por exemplo: "Graças a Deus". Para exemplificar, têm-se as falas de quatro longevos a seguir:

Graças a Deus, eu estou ótima (Camélia, 83 anos).

Graças a Deus, eu tenho uma vida boa! Peço a Deus pra ele me dá saúde pra eu viver muitos anos. Minha vida é boa! Graças a Deus, eu tenho minha vida boa (Angélica, 83 anos).

Graças a Deus, eu sou sadia, não sou doente, né?! Agora, quando a pessoa idosa é doente, depende dos outros pra se locomover, aí é difícil, né?! Mas, graças a Deus, eu sou uma pessoa disposta e espero ser disposta até os cem anos (Rosa, 81 anos).

Vivo a velhice, graças a Deus, muito bem! Tenho minha casa, não devo nada a ninguém, não dependo de ninguém, isso é bom, não é?! (Hortência, 85 anos).

A frequência dessas expressões idiomáticas nas narrativas dos idosos demonstra a reverência a Deus e a gratidão por vivenciar a velhice. De acordo com Chaves e Gil (2015), a vivência da espiritualidade na velhice confere qualidade de vida por intermédio da esperança, à medida que os idosos conseguem desenvolver expectativas positivas e enfrentar a realidade e as incertezas do futuro, por isso, ter um envelhecimento bem- 
-sucedido denota valor e importância à vivência da espiritualidade nessa fase da vida. Isso explica o porquê de a expressão "Graças a Deus" ser recorrente nas falas das pessoas mais velhas.

Nesse sentido, a espiritualidade e a crença em um Deus conferem sentido à vida para os que se deparam com a velhice, em especial, para aqueles cuja finitude se aproxima, por isso, a espiritualidade se torna fundamental nesse momento da vida, conferindo uma proteção especial na velhice (BIOLCHI et al., 2014; CAUDURO et al., 2010).

\section{Conclusões}

Por meio deste estudo, foi possível analisar as percepções dos idosos longevos sobre a longevidade e compreender como eles enxergam o processo de envelhecer. Constatou-se que a percepção do envelhecer está intimamente associada com a espiritualidade e com a crença em algo superior, em Deus, evidenciando que a velhice é o tempo de reverência e agradecimento a Deus, pois envelhecer de maneira saudável, com autonomia e disposição, é um privilégio e uma dádiva de Deus.

Portanto, verificou-se que a espiritualidade na velhice, embora seja vivenciada de forma pessoal e privada, é bastante valorizada pelos idosos, tendo em vista que as percepções sobre o envelhecer foram nitidamente marcadas por uma concepção religiosa, demonstrando o valor e a importância da vivência e da fé em Deus nessa fase da vida, fortalecendo-os e dando significado às suas vidas.
Os achados deste estudo são de grande relevância para uma melhor compreensão sobre o envelhecer, pois a velhice deve ser compreendida não somente em seus aspectos biológicos, mas também em seus aspectos psicológicos, sociais, econômicos, culturais e espirituais. Assim, este estudo reafirma a importância da realização de novos estudos com idosos longevos e da inclusão do tema "espiritualidade" nos estudos sobre envelhecimento, pois se comprovou a escassez na literatura nacional em relação à espiritualidade dos idosos longevos.

Assim, sugere-se que novos estudos envolvendo idosos longevos sejam realizados, para que haja uma melhor compreensão da velhice, uma vez que estudar essa faixa etária, que é a que mais cresce no Brasil, pode aprimorar as políticas públicas de saúde e valorizar a espiritualidade, de modo a alcançar um cuidado mais humanizado, que promova a saúde e a qualidade de vida dos idosos.

\section{Longevity and spirituality: aging as a gift from God}

\section{Abstract}

Aging is perceived by some elderly people as a divine grace, a spiritual meeting and a reverence for God. Thus, this study is intended to analyze the perceptions of long-lived elderly people about the aging process. This is an exploratory-descriptive and qualitative research, using the thematic oral history technique and the NVivo software for data analysis. The interviews

RBCEH, Passo Fundo, v. 14, n. 2, p. 159-168, maio/ago. 2017 
were performed in the period from January to May 2015. It was attended by 10 long-lived elderly people enrolled in a Family Health Unit from the city of Vitória da Conquista, Bahia, who complied with the following inclusion criteria: being aged 80 years or over, being functionally independent and being a user of the chosen FHU. For the long-lived elderly people, aging is associated with spirituality and the belief that old age is a gift from God. This study restates the importance of further studies with long-lived elderly people and the inclusion of the issue of spirituality in the studies on aging.

Keywords: Aging. Spirituality. Old age.

\section{Referências}

BARDIN, L. Análise de conteúdo. São Paulo: Edições 70, 2011.

BARROS, M. M. L. Testemunho de vida: um estudo antropológico de mulheres na velhice. In:___ (Org.). Velhice ou terceira idade? Estudos antropológicos sobre identidade, memória e política. 4. ed. 3. reimpr. Rio de Janeiro: FGV, 2013. p. 113-168.

BIOLCHI, C. S. et al. Vida e velhice aos 100 anos de idade: percepções na fala dos idosos. Estudos Interdisciplinares sobre o Envelhecimento, Porto Alegre, RS, v. 19, n. 2, p. 583-598, ago. 2014.

BRANDÃO, V. M. A. T. Longevidade e espiritualidade: narrativas autobiográficas. São Paulo: Centro Universitário São Camilo; Pontifícia Universidade Católica de São Paulo, 2011.

BRASIL. Em 10 anos, cresce número de idosos no Brasil. 2016. Disponível em: <http://www. brasil.gov.br/economia-e-emprego/2016/12/em-10-anos-cresce-numero-de-idosos-no-brasil>. Acesso em: 12 ago. 2017.
CAUDURO, A. et al. Religiosidade e espiritualidade. In: TERRA, N. L. et al. (Org.). Envelhecimento e suas múltiplas áreas do conhecimento. Porto Alegre: EDIPUCRS, 2010. p. 61-66.

CHAVES, L. J.; GIL, C. A. Concepções de idosos sobre espiritualidade relacionada ao envelhecimento e qualidade de vida. Ciência \& Saúde Coletiva, Rio de Janeiro, RJ, v. 20, n. 12, p. 3641-3652, dez. 2015.

CONCEIÇÃO, L. F. L. Saúde do idoso: orientações ao cuidador acamado. Revista Médica Minas Gerais, Belo Horizonte, MG, v. 20, n. 1, p. 81-91, jan./mar. 2010.

FAORO, R. Os donos do poder. Porto Alegre: Globo, 1958.

FREITAS, C. M.; QUEIROZ, T. A.; SOUSA, J. A. V. O significado da velhice e da experiência de envelhecer para os idosos. Revista da Escola de Enfermagem USP, São Paulo, v. 44, n. 2, p. 407-412, abr./jul. 2010.

FRUMI, C.; CELICH, K. L. S. O olhar do idoso frente ao envelhecimento e à morte. Revista Brasileira de Ciências do Envelhecimento Humano, Passo Fundo, v. 3, n. 2, p. 92-100, jul./ dez. 2006.

GALL, T. L. et al. Spirituality and religiousness: a diversity of definitions. Journal Spiritual Mental Health, v. 13, n. 3, p. 158-181, 2011.

GUTZ, L; CAMARGO, B. V. Espiritualidade entre idosos mais velhos: um estudo de representações sociais. Revista Brasileira de Geriatria e Gerontologia, São Paulo, v. 16, n. 4, p. 793-804, out./dez. 2013.

LUCCHETTI, G. et al. O idoso e sua espiritualidade: impacto sobre diferentes aspectos do envelhecimento. Revista Brasileira de Geriatria e Gerontologia, São Paulo, v. 14, n. 1, p. 159-167, jan./fev. 2011.

MELLO, M. A.; ARAÚJO, C. A. Velhice e espiritualidade na perspectiva da Psicologia Analítica. Boletim da Academia Paulista de Psicologia, São Paulo, v. 33, n. 84, p. 118-141, 2013. 
MEIHY, J. C. S. B. Manual de história oral. 5. ed. São Paulo: Loyola, 2005.

MINAYO, M. C. S.; COIMBRA JÚNIOR, C. E. A. Antropologia, saúde e envelhecimento. Rio de Janeiro: Fiocruz, 2002.

QRS INTERNACIONAL. NVivo10 for Windows. 2014. Disponível em: <http://download. qsrinternational.com/Document/NVivo10/ NVivo10-Getting-Started-Guide-Portuguese. pdf $>$. Acesso em: 12 jul. 2015.

SANTOS, D. F. et al. A arte de morar só e ser feliz na velhice. Revista Kairós Gerontologia, São Paulo, v. 12, n. 8, p. 109-123, jan./mar. 2010.

SANTOS, D. V. et al. Velhice - considerações sobre o envelhecimento: imagens no espelho. Nova Perspectiva Sistêmica, Rio de Janeiro, v. 23, n. 48, p. 80-94, ago. 2014.

TOVAR-MURRAY, D. The multiple determinants of religious behaviors and spiritual beliefs on well-being. Journal Spiritual Mental Health, v. 13, n. 3, p. 182-192, 2011.

VASCONCELOS, A. L.; SOUZA FILHO, A. R. Bananal: trabalho e vivência em uma comunidade de negros. Politéia, Vitória da Conquista, v. 1 , n. 1 , p. 247-268, jan. 2001. 